University of Nebraska - Lincoln

DigitalCommons@University of Nebraska - Lincoln

Faculty Papers and Publications in Animal

Science

Animal Science Department

April 2000

\title{
Parameter estimates for genetic effects on carcass traits of Korean Native Cattle
}

J. W. Lee

University of Nebraska-Lincoln

S. B. Choi

Livestock Improvement Department, National Livestock Research Institute, RDA, Cheonan, 330-800, Korea

J. S. Kim

Livestock Improvement Department, National Livestock Research Institute, RDA, Cheonan, 330-800, Korea

Jeffrey F. Keown

University of Nebraska-Lincoln, jkeown1@unl.edu

L. Dale Van Vleck

University of Nebraska-Lincoln, dvan-vleck1@unl.edu

Follow this and additional works at: https://digitalcommons.unl.edu/animalscifacpub

Part of the Animal Sciences Commons

Lee, J. W.; Choi, S. B.; Kim, J. S.; Keown, Jeffrey F.; and Van Vleck, L. Dale, "Parameter estimates for genetic effects on carcass traits of Korean Native Cattle" (2000). Faculty Papers and Publications in Animal Science. 218.

https://digitalcommons.unl.edu/animalscifacpub/218

This Article is brought to you for free and open access by the Animal Science Department at DigitalCommons@University of Nebraska - Lincoln. It has been accepted for inclusion in Faculty Papers and Publications in Animal Science by an authorized administrator of DigitalCommons@University of Nebraska - Lincoln. 


\title{
Parameter estimates for genetic effects on carcass traits of Korean Native Cattle ${ }^{1}$
}

\author{
J. W. Lee*, S. B. Choi $\dagger$, J. S. Kim $\dagger$, J. F. Keown*,2, and L. D. Van Vleck \\ *Department of Animal Science, University of Nebraska, Lincoln 68583-0908; †Livestock Improvement \\ Department, National Livestock Research Institute, RDA, Cheonan, 330-800, Korea; and $\ddagger$ USDA, ARS, \\ Roman L. Hruska U.S. Meat Animal Research Center, Lincoln, NE 68583-0908
}

\begin{abstract}
Data $(\mathrm{n}=1,746)$ collected from 1985 through 1995 on Korean Native Cattle by the National Livestock Research Institute of Korea were used to estimate genetic parameters for marbling score, dressing percentage, and longissimus muscle area, with backfat thickness, slaughter age, or slaughter weight as covariates. Estimates were obtained with REML. Model 1 included animal genetic and residual random effects. Model 2 was extended to include an uncorrelated random effect of the dam. Model 3 was based on Model 1 but also included sire $\times$ region $\times$ year-season interaction effects. Model 4 combined Models 2 and 3. All models included fixed effects for region $\times$ year-season and age of dam $\times$ sex combinations. From single-trait analyses, estimates of heritability with covariates to adjust for backfat thickness, slaughter age, and slaughter weight from Model 4 were, respectively, .10, .08, and .01 for marbling score; .09, .12, and .16 for dressing percentage; and $.18, .17$, and .24 for longissimus muscle area. From three-trait analyses, estimates of genetic correlations between marbling score and dressing percentage, marbling score and longissimus muscle area, and dressing percentage and longissimus muscle area were, respec-
\end{abstract}

tively, $-.99, .20$, and -.11 with backfat thickness as covariate; $-.88, .47$, and .01 with slaughter age as covariate; and $-.03, .39$, and .91 with slaughter weight as covariate. Results of this study suggest that choice of covariate (backfat thickness, slaughter age, or slaughter weight) for the model seems to be important for carcass traits for Korean Native Cattle. Including sire $\times$ region $\times$ year-season interaction effects in the model for marbling score and dressing percentage may be important because whether sire $\times$ region $\times$ year-season interaction effects were in the model affected estimates of other variance components for the three carcass traits. Whether the maternal effect was in the model had little effect on estimates of other parameters. With backfat thickness and slaughter age end points, selection for increasing marbling score would be expected to result in decreasing dressing percentage for Korean Native Cattle. With slaughter weight as a covariate for end point, increased longissimus muscle area would be associated with increased dressing percentage, and increased marbling score would be related to increased longissimus muscle area. The differences in estimates associated with choice of end point, however, need further study.

Key Words: Beef Cattle, Genetic Correlation, Heritability, Meat Quality

(O)2000 American Society of Animal Science. All rights reserved.

J. Anim. Sci. 2000. 78:1181-1190

\section{Introduction}

Carcass traits in beef cattle are important determinants of meat quality. Numerous studies of carcass traits of beef cattle have found the genetic correlation between marbling score and longissimus muscle area to be negative (Koots et al., 1994b). Marshall (1994) suggested that genetic correlation between longissimus muscle area and fat thickness with an age-constant covariate was nega-

\footnotetext{
${ }^{1}$ Published as paper no. 12713, Journal Ser., Nebraska Agric. Res. Div., Univ. of Nebraska, Lincoln.

${ }^{2}$ Correspondence: A218 Animal Sciences (phone: 402/472-6453; fax: 402/472-6362; E-mail: jkeown@unlnotes.unl.edu).

Received August 3, 1999.

Accepted December 1, 1999.
}

tive. Several studies have reported estimates of direct heritabilities for marbling score to be moderate (Koots et al., 1994a).

When data are adjusted (covariate) to a constant age or physiological end point, estimates of heritability may be influenced by the covariate in the model. Benyshek (1981) reported that use of either constant weight or constant age had little effect on heritability estimates. The review of Koots et al. (1994a) found that average estimates of heritability for carcass traits did not differ significantly with different adjustments (age, live weight, and fat depth). However, heritability estimates with adjusted fat depth were somewhat greater than age- and weight-adjusted estimates.

The objective of this study of Korean Native Cattle was to estimate parameters associated with genetic ef- 
fects for marbling score, dressing percentage, and longissimus muscle area with backfat thickness, slaughter age, or slaughter weight as covariates in the model. These estimates are needed for genetic evaluations of these carcass traits for Hanwoo, the Korean Native Cattle.

\section{Materials and Methods}

Data were collected from 1985 through 1995 by the National Livestock Research Institute in Rural Development Administration of Korea for marbling score (coded from 1 to 5, extremely low to extremely high, respectively), dressing percentage (\%), and longissimus muscle (ribeye) area $\left(\mathrm{cm}^{2}\right)$ with backfat thickness at slaughter $(\mathrm{mm})$, slaughter age $(\mathrm{d})$, or slaughter weight $(\mathrm{kg})$ as possible covariates. The data set used included only animals that had all three traits and all three covariates measured so that the effects of the three different covariates on estimates of parameters could be compared. Total number of animals in pedigrees including animals with records was 3,243 for the data set with all traits and covariates measured.

Region was classified by location at birth, either on an experiment station or on a farm. Farm codes were not available. Average slaughter age and weight were $682 \mathrm{~d}$ and $537 \mathrm{~kg}$, respectively. Two calving seasons centered about April and October. Ages of dams ranged from 2 to $13 \mathrm{yr}$.

Sires and dams (unique assigned identification was used for records for which actual dam identification was missing) were identified for each animal. Numbers of records (including sires, dams, and assigned dams) and unadjusted means and standard deviations by trait are given in Table 1.

Four single-trait animal models, each with one of the three different covariates, were initially used to establish starting values for use with multiple-trait animal models. Region $\times$ year-season and age of dam $(\mathrm{yr}) \times$ sex combinations were fixed effects for all models. Table 2 summarizes parameters that were estimated with the four models. Analyses of single traits were based on the following models:

Table 1. Number of observations, unadjusted means ${ }^{\mathrm{a}}$, and standard deviations (SD) by trait

\begin{tabular}{lccc}
\hline & \multicolumn{3}{c}{ Data with all traits ${ }^{\mathrm{b}}$ and covariates measured } \\
\cline { 2 - 4 } Item & MSC & DRP & LMA \\
\hline Means & 1.93 & 58.15 & 79.15 \\
SD & 1.26 & 2.14 & 10.16 \\
Records & 1,746 & 1,746 & 1,746 \\
Sires & & 170 & 170 \\
Dams & 170 & 1,327 & 1,327 \\
SRYS $^{\mathrm{d}}$ & 1,327 & 202 & 202 \\
\hline
\end{tabular}

${ }^{a}$ Records unadjusted for the model effects.

${ }^{\mathrm{b}} \mathrm{MSC}=$ marbling score, $\mathrm{DRP}=$ dressing percentage $(\%)$, and LMA $=$ longissimus muscle area $\left(\mathrm{cm}^{2}\right)$.

${ }^{\mathrm{c}}$ All sires were known.

${ }^{\mathrm{d} D a m s}$ included assigned dams. Number of assigned dams was 415.

${ }^{\mathrm{e}} \mathrm{SRYS}=$ sire $\times$ region $\times$ year-season combinations.
Table 2. Parameters estimated with the four models

\begin{tabular}{lllll}
\hline \hline & \multicolumn{4}{c}{ Parameter $^{\mathrm{a}}$} \\
\cline { 2 - 5 } Model & $\sigma_{a}^{2}$ & $\sigma_{p}^{2}$ & $\sigma_{q}^{2}$ & $\sigma_{e}^{2}$ \\
\hline 1 & $\mathrm{X}$ & & & $\mathrm{X}$ \\
2 & $\mathrm{X}$ & $\mathrm{X}$ & & $\mathrm{X}$ \\
3 & $\mathrm{X}$ & & $\mathrm{X}$ & $\mathrm{X}$ \\
4 & $\mathrm{X}$ & $\mathrm{X}$ & $\mathrm{X}$ & $\mathrm{X}$ \\
\hline
\end{tabular}

${ }^{\mathrm{a}} \sigma_{a}^{2}=$ direct genetic variance, $\sigma_{p}^{2}=$ variance due to effect of dam (maternal genetic and permanent environmental effects), $\sigma_{q}^{2}=$ variance of sire $\times$ region $\times$ year-season interaction effects, and $\sigma_{e}^{2}=$ variance of temporary environmental effects. Fixed effects in the model were region $\times$ year-season and age of dam $\times$ sex combinations.

Model 1 included genetic and residual effects:

$$
\boldsymbol{y}=\boldsymbol{X} \boldsymbol{\beta}+\boldsymbol{Z a}+\boldsymbol{e},
$$

where

$\boldsymbol{y}$ is a $\mathrm{N} \times 1$ vector of observations,

$\boldsymbol{\beta}$ is a vector of fixed effects (region $\times$ year-season and age of dam $\times$ sex combinations),

$\boldsymbol{a}$ is vector of genetic effects,

$\boldsymbol{e}$ is vector of residual effects, and

$\boldsymbol{X}$ and $\boldsymbol{Z}$ are known matrices relating observations in $\boldsymbol{y}$ to fixed and random effects.

Model 2 was based on Model 1 but extended to include a maternal effect of the dam:

$$
\boldsymbol{y}=\boldsymbol{X} \boldsymbol{\beta}+\boldsymbol{Z a}+\boldsymbol{W}_{1} \boldsymbol{p}+\boldsymbol{e},
$$

where

$\boldsymbol{p}$ is vector of random, uncorrelated maternal effects and $\boldsymbol{W}_{1}$ is a known matrix relating observations in $\boldsymbol{y}$ to effects in $\boldsymbol{p}$.

Random effects in Model 3 included genetic, the sire $\times$ region $\times$ year-season interaction, and residual effects:

$$
\boldsymbol{y}=\boldsymbol{X} \boldsymbol{\beta}+\boldsymbol{Z a}+\boldsymbol{W}_{2} \boldsymbol{q}+\boldsymbol{e},
$$

where

$\boldsymbol{q}$ is vector of sire $\times$ region $\times$ year-season interaction effects and

$\boldsymbol{W}_{2}$ is a known matrix relating observations in $\boldsymbol{y}$ to effects in $\boldsymbol{q}$.

Model 4 was based on Model 3 but extended to include a maternal effect of the dam:

$$
\boldsymbol{y}=\boldsymbol{X} \boldsymbol{\beta}+\boldsymbol{Z} \boldsymbol{a}+\boldsymbol{W}_{1} \boldsymbol{p}+\boldsymbol{W}_{2} \boldsymbol{q}+\boldsymbol{e},
$$

For all models: 


$$
\mathrm{E}[y]=\mathbf{X} \beta
$$

and the (co)variance structure for Model 4 was:

$$
\boldsymbol{V}\left[\begin{array}{l}
\boldsymbol{a} \\
\boldsymbol{p} \\
\boldsymbol{q} \\
\boldsymbol{e}
\end{array}\right]=\left[\begin{array}{llll}
\boldsymbol{A} \sigma_{a}^{2} & 0 & 0 & 0 \\
0 & \boldsymbol{I}_{N_{d}} \sigma_{p}^{2} & 0 & 0 \\
0 & 0 & \boldsymbol{I}_{N_{s}} \sigma_{q}^{2} & 0 \\
0 & 0 & 0 & \boldsymbol{I}_{N} \sigma_{e}^{2}
\end{array}\right]
$$

where

$$
\begin{aligned}
N_{d}= & \text { number of dams } \\
N_{s}= & \text { number of sire } \times \text { region } \times \text { year-season combina- } \\
& \text { tions }, \\
N= & \text { number of records } \\
\boldsymbol{A}= & \text { numerator relationship matrix among animals in } \\
& \text { the pedigree, and } \\
\boldsymbol{I}= & \text { identity matrix of appropriate order. }
\end{aligned}
$$

Estimates of genetic parameters were obtained with derivative-free REML (Smith and Graser, 1986; Graser et al., 1987). The program (Boldman et al., 1995) was restarted with the estimates at previous apparent convergence as initial values to help ensure a global minimum was found, i.e., -2 times the logarithm of the likelihood did not change to the third decimal after consecutive restarts.

\section{Results and Discussion}

\section{Marbling Score}

With any of the covariates used in the models, models including sire $\times$ region $\times$ year-season interaction effects (Models 3 and 4) resulted in greatly reduced estimates of variance due to genetic effects compared with Models 1 and 2 , which ignored any effects of sire $\times$ region $\times$ yearseason interaction in the model (Table 3). The reduction was greatest with slaughter weight. This result suggests that the interaction may be accounting for contemporary group effects. The data did not include other information to use to form contemporary groups. The interaction effects may be also an indication of misidentification of sires, as shown by Lee and Pollak (1997). The estimate of variance due to maternal effects was near zero, so Models 3 and 4 had the same likelihoods and estimates of other parameters.

With the different covariates, the log likelihoods changed greatly from covariate to covariate. Parameter estimates from single-trait analyses for marbling score with three different covariates (backfat thickness, slaughter age, and slaughter weight) for the four models are shown in Table 3. Estimates of direct heritability $\left(h_{a}^{2}\right)$ for marbling score were .35 (Model 1), .35 (Model 2), .10 (Model 3), and .10 (Model 4) with backfat thickness as covariate; $.31, .35, .08$, and .08 with slaughter age as covariate; and $.41, .41, .01$, and .01 with slaughter weight as covariate. The estimates with Models 3 and 4 were smaller than the averages Koots et al. (1994a) reported of .65 with fat depth, .38 with age, and .36 with weight as covariates, respectively. Hirooka et al. (1996) found that with slaughter weight as a covariate, heritability of marbling score was .42 for Japanese Brown Cattle. Pariacote et al. (1998) reported an estimate of heritability of marbling score was .88 without a covariate for American Shorthorn Beef Cattle.

Heritability with slaughter weight as a covariate was much less than when either backfat thickness or slaughter age was used as a covariate in Model 4. However, the estimates of heritability for marbling score with any of the three different covariates in Models 3 and 4 were much smaller than previous reports for other breeds (Koots et al., 1994a). The low estimates may be caused by imprecise data collecting or by the small number of records. The results indicate that choice of covariate in the model (backfat thickness or slaughter age vs slaughter weight) may affect estimates of heritability for marbling score. The decision to use a particular covariate in the model (backfat thickness, slaughter age, or slaughter weight) depends, however, on the purpose of the analysis.

\section{Dressing Percentage}

Estimates of genetic parameters from single-trait analyses for dressing percentage with the three different covariates in the model (backfat thickness, slaughter age, and slaughter weight) and with the four models are reported in Table 4. Estimates of heritability for dressing percentage were .62 (Model 1), .59 (Model 2), .44 (Model 3), and .09 (Model 4) with backfat thickness as covariate; $.64, .60, .48$, and .12 with slaughter age as covariate; and $.69, .66, .54$, and .16 with slaughter weight as covariate. With any of the three covariates in the model, the model that included both general maternal effects and sire $\times$ region $\times$ year-season interaction effects (Model 4 ) resulted in significantly reduced estimates of heritability. Estimates of variance due either to maternal effects or to sire $\times$ region $\times$ year-season interaction effects increased when the other factor was added to the model compared to estimates when only one of those factors was in the model. This pattern was not seen for marbling score or longissimus muscle area. In contrast to estimates of heritability for marbling score, the estimates were somewhat larger with slaughter weight as a covariate than with either backfat thickness or slaughter age as a covariate.

The estimates for Model 4 were less than the averages of estimates summarized by Koots et al. (1994a), who reported weighted mean heritabilities with age and weight as covariates to be .39 and .38 , respectively. The estimates for Models 1, 2, and 3 were larger than those summarized by Koots et al. (1994a). Pariacote et al. (1998) reported an estimate of heritability of dressing percentage of .49 without use of a covariate for American Shorthorn beef cattle. 
Table 3. Estimates of variance components and genetic parameters (standard errors) for marbling score with backfat thickness, slaughter age, or slaughter weight as covariates (all animals with traits and covariates measured)

\begin{tabular}{|c|c|c|c|c|c|c|c|c|c|c|c|c|}
\hline \multirow[b]{3}{*}{ Parameter $^{\mathrm{a}}$} & \multicolumn{12}{|c|}{ Covariate } \\
\hline & \multicolumn{4}{|c|}{ Backfat thickness } & \multicolumn{4}{|c|}{ Slaughter age } & \multicolumn{4}{|c|}{ Slaughter weight } \\
\hline & Model 1 & Model 2 & Model 3 & Model 4 & Model 1 & Model 2 & Model 3 & Model 4 & Model 1 & Model 2 & Model 3 & Model 4 \\
\hline$-2 \log L$ & $1,615.91$ & $1,615.91$ & $1,604.65$ & $1,604.65$ & $1,835.91$ & $1,835.47$ & $1,822.25$ & $1,822.25$ & $2,011.55$ & $2,011.55$ & $1,982.21$ & $1,982.22$ \\
\hline$\sigma_{a}^{2}$ & .313 & .315 & .096 & .094 & .315 & .362 & .085 & .085 & .475 & .475 & .006 & .008 \\
\hline$\sigma_{p}^{2}$ & - & .000 & - & .000 & - & .000 & - & .000 & - & .000 & - & .000 \\
\hline$\sigma_{q}^{2}$ & - & - & .093 & .092 & - & - & .115 & .116 & - & - & .216 & .215 \\
\hline$\sigma_{e}^{2}$ & .593 & .592 & .730 & .731 & .691 & .663 & .839 & .839 & .673 & .673 & .962 & .960 \\
\hline$h_{a}^{2}$ & $\begin{array}{l}.35 \\
(.073)\end{array}$ & $\begin{array}{l}.35 \\
(.082)\end{array}$ & $\begin{array}{l}.10 \\
(.104)\end{array}$ & $\begin{array}{l}.10 \\
(.130)\end{array}$ & $\begin{array}{l}.31 \\
(.068)\end{array}$ & $\begin{array}{l}.35 \\
(.081)\end{array}$ & $\begin{array}{l}.08 \\
(.105)\end{array}$ & $\begin{array}{l}.08 \\
(.135)\end{array}$ & $\begin{array}{l}.41 \\
(.075)\end{array}$ & $\begin{array}{l}.41 \\
(.086)\end{array}$ & $\begin{array}{l}.01 \\
(.088)\end{array}$ & $\begin{array}{l}.01 \\
(.108)\end{array}$ \\
\hline$p^{2}$ & - & $\begin{array}{l}.00 \\
(.049)\end{array}$ & - & $\begin{array}{l}.00 \\
(.052)\end{array}$ & - & $\begin{array}{l}.00 \\
(.049)\end{array}$ & - & $\begin{array}{l}.00 \\
(.053)\end{array}$ & - & $\begin{array}{l}.00 \\
(.049)\end{array}$ & - & $\begin{array}{l}.00 \\
(.047)\end{array}$ \\
\hline$q^{2}$ & - & - & $\begin{array}{l}.10 \\
(.034)\end{array}$ & $\begin{array}{l}.10 \\
(.038)\end{array}$ & - & - & $\begin{array}{l}.11 \\
(.035)\end{array}$ & $\begin{array}{l}.11 \\
(.040)\end{array}$ & - & - & $\begin{array}{l}.18 \\
(.036)\end{array}$ & $\begin{array}{l}.18 \\
(.040)\end{array}$ \\
\hline$e^{2}$ & $\begin{array}{l}.65 \\
(.073)\end{array}$ & $\begin{array}{l}.65 \\
(.074)\end{array}$ & $\begin{array}{l}.79 \\
(.083)\end{array}$ & $\begin{array}{l}.80 \\
(.083)\end{array}$ & $\begin{array}{l}.69 \\
(.068)\end{array}$ & $\begin{array}{l}.65 \\
(.073)\end{array}$ & $\begin{array}{l}.81 \\
(.083)\end{array}$ & $\begin{array}{l}.81 \\
(.084)\end{array}$ & $\begin{array}{l}.59 \\
(.075)\end{array}$ & $\begin{array}{l}.59 \\
(.075)\end{array}$ & $\begin{array}{l}.81 \\
(.070)\end{array}$ & $\begin{array}{l}.81 \\
(.071)\end{array}$ \\
\hline
\end{tabular}

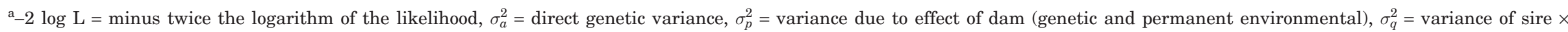

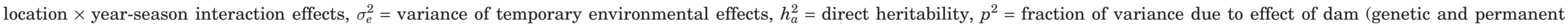
environmental), $q^{2}=$ fraction of variance due to sire $\times$ region $\times$ year-season interaction effects, and $e^{2}=$ fraction of variance due to residual effects. 
Table 4. Estimates of variance components and genetic parameters (standard errors) for dressing percentage with backfat thickness, slaughter age, or slaughter weight as covariates (all animals with traits and covariates measured)

\begin{tabular}{|c|c|c|c|c|c|c|c|c|c|c|c|c|}
\hline \multirow[b]{3}{*}{ Parameter $^{\mathrm{a}}$} & \multicolumn{12}{|c|}{ Covariate } \\
\hline & \multicolumn{4}{|c|}{ Backfat thickness } & \multicolumn{4}{|c|}{ Slaughter age } & \multicolumn{4}{|c|}{ Slaughter weight } \\
\hline & Model 1 & Model 2 & Model 3 & Model 4 & Model 1 & Model 2 & Model 3 & Model 4 & Model 1 & Model 2 & Model 3 & Model 4 \\
\hline$-2 \log L$ & $4,016.76$ & $4,016.54$ & $4,012.96$ & $4,008.47$ & $4,057.37$ & $4,057.06$ & $4,054.11$ & $4,049.80$ & $3,975.01$ & $3,974.87$ & $3,971.89$ & $3,968.44$ \\
\hline$\sigma_{a}^{2}$ & 2.39 & 2.28 & 1.73 & .33 & 2.53 & 2.37 & 1.92 & .49 & 2.64 & 2.52 & 2.09 & .62 \\
\hline$\sigma_{p}^{2}$ & - & .10 & - & .57 & - & .12 & - & .59 & - & .08 & - & .56 \\
\hline$\sigma_{q}^{2}$ & - & - & .23 & .50 & - & - & .22 & .48 & - & - & .21 & .48 \\
\hline$\sigma_{e}^{2}$ & 1.49 & 1.49 & 1.93 & 2.44 & 1.43 & 1.45 & 1.85 & 2.36 & 1.18 & 1.21 & 1.55 & 2.12 \\
\hline$h_{a}^{2}$ & $\begin{array}{l}.62 \\
(.085)\end{array}$ & $\begin{array}{l}.59 \\
(.102)\end{array}$ & $\begin{array}{l}.44 \\
(.135)\end{array}$ & $\begin{array}{l}.09 \\
(.159)\end{array}$ & $\begin{array}{l}.64 \\
(.085)\end{array}$ & $\begin{array}{l}.60 \\
(.103)\end{array}$ & $\begin{array}{l}.48 \\
(.133)\end{array}$ & $\begin{array}{l}.12 \\
(.135)\end{array}$ & $\begin{array}{l}.69 \\
(.085)\end{array}$ & $\begin{array}{l}.66 \\
(.107)\end{array}$ & $\begin{array}{l}.54 \\
(.131)\end{array}$ & $\begin{array}{l}.16 \\
(.108)\end{array}$ \\
\hline$p^{2}$ & - & $\begin{array}{l}.03 \\
(.054)\end{array}$ & - & $\begin{array}{l}.15 \\
(.059)\end{array}$ & - & $\begin{array}{l}.03 \\
(.054)\end{array}$ & - & $\begin{array}{l}.15 \\
(.064)\end{array}$ & - & $\begin{array}{l}.02 \\
(.054)\end{array}$ & - & $\begin{array}{l}.15 \\
(.070)\end{array}$ \\
\hline$q^{2}$ & - & - & $\begin{array}{l}.06 \\
(.037)\end{array}$ & $\begin{array}{l}.13 \\
(.045)\end{array}$ & - & - & $\begin{array}{l}.06 \\
(.036)\end{array}$ & $\begin{array}{l}.12 \\
(.049)\end{array}$ & - & - & $\begin{array}{l}.06 \\
(.037)\end{array}$ & $\begin{array}{l}.13 \\
(.056)\end{array}$ \\
\hline$e^{2}$ & $\begin{array}{l}.38 \\
(.085)\end{array}$ & $\begin{array}{l}.38 \\
(.083)\end{array}$ & $\begin{array}{l}.49 \\
(.110)\end{array}$ & $\begin{array}{l}.63 \\
(.094)\end{array}$ & $\begin{array}{l}.36 \\
(.085)\end{array}$ & $\begin{array}{l}.37 \\
(.083)\end{array}$ & $\begin{array}{l}.46 \\
(.109)\end{array}$ & $\begin{array}{l}.60 \\
(.105)\end{array}$ & $\begin{array}{l}.31 \\
(.085)\end{array}$ & $\begin{array}{l}.32 \\
(.084)\end{array}$ & $\begin{array}{l}.40 \\
(.107)\end{array}$ & $\begin{array}{l}.56 \\
(.121)\end{array}$ \\
\hline
\end{tabular}

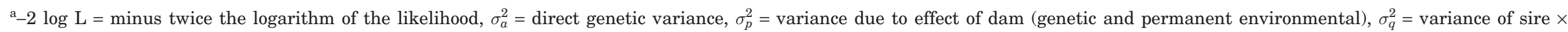

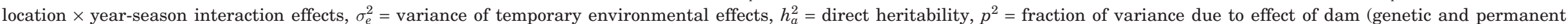
environmental), $q^{2}=$ fraction of variance due to sire $\times$ region $\times$ year-season interaction effects, and $e^{2}=$ fraction of variance due to residual effects. 
Table 5. Estimates of variance components and genetic parameters (standard errors) for longissimus muscle with backfat thickness, slaughter age, or slaughter weight as covariates (all animals with traits and covariates measured)

\begin{tabular}{|c|c|c|c|c|c|c|c|c|c|c|c|c|}
\hline \multirow[b]{3}{*}{ Parameter $^{\mathrm{a}}$} & \multicolumn{12}{|c|}{ Covariate } \\
\hline & \multicolumn{4}{|c|}{ Backfat thickness } & \multicolumn{4}{|c|}{ Slaughter age } & \multicolumn{4}{|c|}{ Slaughter weight } \\
\hline & Model 1 & Model 2 & Model 3 & Model 4 & Model 1 & Model 2 & Model 3 & Model 4 & Model 1 & Model 2 & Model 3 & Model 4 \\
\hline$-2 \log L$ & $9,275.02$ & $9,275.02$ & $9,272.22$ & $9,272.17$ & $9,284.71$ & $9,284.71$ & $9,282.08$ & $9,282.02$ & $8,798.41$ & $8,798.41$ & $8,797.32$ & $8,797.31$ \\
\hline$\sigma_{a}^{2}$ & 25.09 & 25.19 & 15.55 & 14.06 & 24.57 & 24.53 & 15.29 & 13.79 & 19.71 & 19.64 & 14.68 & 14.13 \\
\hline$\sigma_{p}^{2}$ & - & .02 & - & .88 & - & .00 & - & .90 & - & .00 & - & .29 \\
\hline$\sigma_{q}^{2}$ & - & - & 3.62 & 3.86 & - & - & 3.43 & 3.81 & - & - & 1.87 & 1.94 \\
\hline$\sigma_{e}^{2}$ & 53.91 & 53.77 & 60.08 & 60.31 & 54.23 & 54.22 & 60.33 & 60.60 & 39.85 & 38.82 & 43.15 & 43.28 \\
\hline$h_{a}^{2}$ & $\begin{array}{l}.32 \\
(.068)\end{array}$ & $\begin{array}{l}.32 \\
(.076)\end{array}$ & $\begin{array}{l}.20 \\
(.110)\end{array}$ & $\begin{array}{l}.18 \\
(.146)\end{array}$ & $\begin{array}{l}.31 \\
(.068)\end{array}$ & $\begin{array}{l}.31 \\
(.075)\end{array}$ & $\begin{array}{l}.19 \\
(.109)\end{array}$ & $\begin{array}{l}.17 \\
(.145)\end{array}$ & $\begin{array}{l}.33 \\
(.069)\end{array}$ & $\begin{array}{l}.33 \\
(.077)\end{array}$ & $\begin{array}{l}.25 \\
(.115)\end{array}$ & $\begin{array}{l}.24 \\
(.158)\end{array}$ \\
\hline$p^{2}$ & - & $\begin{array}{l}.00 \\
(.049)\end{array}$ & - & $\begin{array}{l}.01 \\
(.055)\end{array}$ & - & $\begin{array}{l}.00 \\
(.049)\end{array}$ & - & $\begin{array}{l}.01 \\
(.055)\end{array}$ & - & $\begin{array}{l}.00 \\
(.047)\end{array}$ & - & $\begin{array}{l}.01 \\
(.057)\end{array}$ \\
\hline$q^{2}$ & - & - & $\begin{array}{l}.05 \\
(.031)\end{array}$ & $\begin{array}{l}.05 \\
(.038)\end{array}$ & - & - & $\begin{array}{l}.04 \\
(.031)\end{array}$ & $\begin{array}{l}.05 \\
(.038)\end{array}$ & - & - & $\begin{array}{l}.03 \\
(.032)\end{array}$ & $\begin{array}{l}.03 \\
(.040)\end{array}$ \\
\hline$e^{2}$ & $\begin{array}{l}.68 \\
(.068)\end{array}$ & $\begin{array}{l}.68 \\
(.070)\end{array}$ & $\begin{array}{l}.76 \\
(.088)\end{array}$ & $\begin{array}{l}.76 \\
(.089)\end{array}$ & $\begin{array}{l}.69 \\
(.068)\end{array}$ & $\begin{array}{l}.69 \\
(.069)\end{array}$ & $\begin{array}{l}.76 \\
(.088)\end{array}$ & $\begin{array}{l}.77 \\
(.089)\end{array}$ & $\begin{array}{l}.67 \\
(.069)\end{array}$ & $\begin{array}{l}.67 \\
(.070)\end{array}$ & $\begin{array}{l}.72 \\
(.092)\end{array}$ & $\begin{array}{l}.73 \\
(.095)\end{array}$ \\
\hline
\end{tabular}

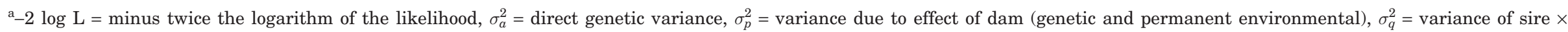

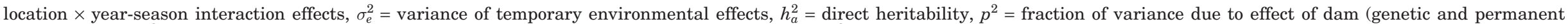
environmental), $q^{2}=$ fraction of variance due to sire $\times$ region $\times$ year-season interaction effects, and $e^{2}=$ fraction of variance due to residual effects. 
Heritability with slaughter weight as a covariate was greater than when either backfat thickness or slaughter age was used as the covariate in Model 4. This result indicates that choice of covariate in the model (backfat thickness or slaughter age vs slaughter weight) affects estimates of heritability for dressing percentage. Likelihood ratio tests showed that Model 4 was a significantly better fit than Models 1, 2, and 3 for dressing percentage with backfat thickness, slaughter age, or slaughter weight as covariates $(P<.05)$.

\section{Longissimus Muscle Area}

Estimates of genetic parameters from single-trait analyses for longissimus muscle area with the three covariates and the four models are reported in Table 5 . Estimates of heritability for longissimus muscle area were .32 (Model 1), .32 (Model 2), .20 (Model 3), and .18 (Model 4) with backfat thickness as covariate; .31, .31, .19 , and .17 with slaughter age as covariate; and .33 , $.33, .25$, and .24 with slaughter weight as covariate. The estimates with the slaughter weight covariate are similar to those of Hirooka et al. (1996), who found that with a covariate for slaughter weight the estimate of heritability was .27 for Japanese Brown cattle. The estimates were smaller than the averages in Koots et al. (1994a), who reported weighted mean heritabilities with fat depth, age, and weight as covariates to be $.40, .42$, and .41, respectively. Marshall (1994) estimated average heritability from the recent literature for longissimus muscle area to be .37 .

With any of the covariates used in the model, the models including sire $\times$ region $\times$ year-season interaction effects (Models 3 and 4) resulted in reduced estimates of variance due to genetic effects compared with Models 1 and 2 , which ignored any effects of sire $\times$ region $\times$ yearseason interaction in the model, although the likelihoods were similar for all models. The reduction in the estimate of heritability was much less than for marbling score and dressing percentage. These results indicate that choice of covariate in the model (backfat thickness or slaughter age vs slaughter weight) may affect estimates of heritability for longissimus muscle area. Likelihood ratio tests showed that Model 4, however, was not a significantly better fit than any of the other models for longissimus muscle area with any of the covariates $(P>.05)$.

\section{Genetic Correlations}

Model 4 was used for the three-trait analyses. Parameter estimates for marbling score, dressing percentage, and longissimus muscle area are shown in Table 6 . The top part of the table includes all data with all traits and all covariates fitted. The bottom of the table includes all data with all traits measured but without using a covariate for end point in the model. The last analysis was done in an attempt to understand why the estimates with slaughter weight as covariate were so different from estimates with either backfat thickness or slaughter age

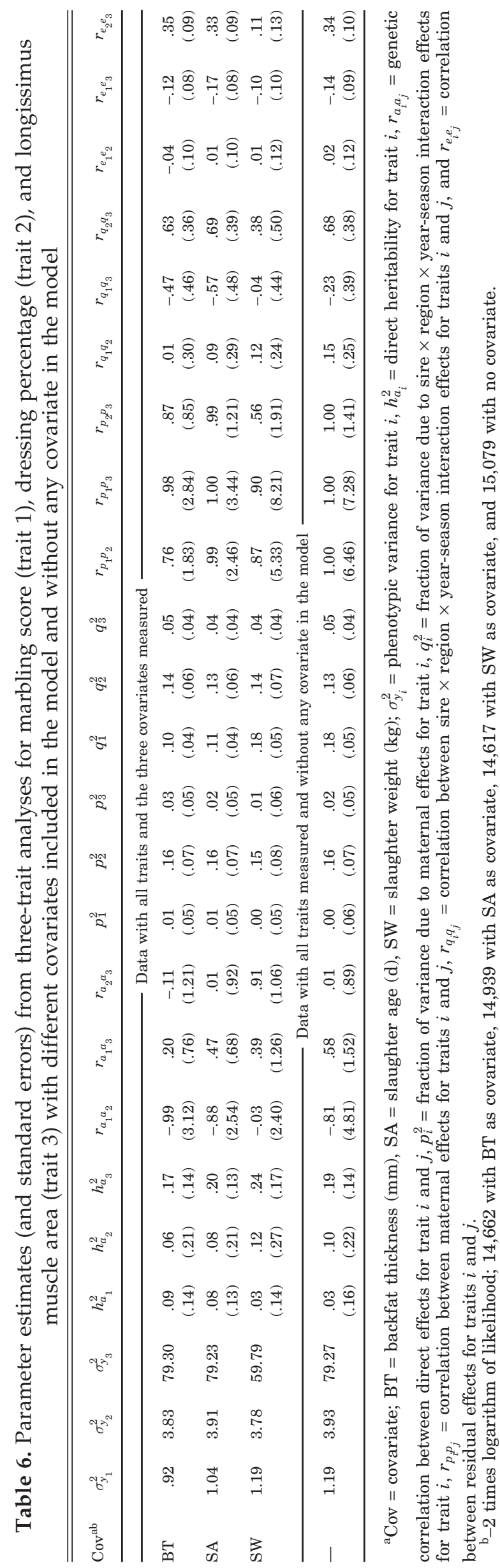


covariates. No insight was gained, but the estimates are reported nevertheless.

In general, estimates of heritabilities from multipletrait analyses were somewhat smaller than those from single-trait analyses, except that the estimate of heritability for longissimus muscle with slaughter age as a covariate (.20) was greater than that from single-trait analysis (.17).

Estimates of genetic correlations between marbling score and dressing percentage, marbling score and longissimus muscle area, and dressing percentage and longissimus muscle area were, respectively, $-.99, .20$, and -.11 with backfat thickness as covariate; $-.88, .47$, and .01 with slaughter age as covariate; and -.03, .39 , and .91 with slaughter weight as covariate. With either backfat thickness or slaughter age as a covariate in the model, the estimates of genetic correlation between marbling score and dressing percentage were highly negative, compared to near zero with slaughter weight as the covariate. Similarly, the estimates of genetic correlations between dressing percentage and longissimus muscle area were greatly different depending on the covariate used as the end point: -.11 and .01 with backfat thickness and slaughter age covariates and .91 with slaughter weight covariate. These results indicate that selection for increasing marbling score would result in decreasing dressing percentage at constant physiological (fat con- stant) or chronological age. These estimates do not agree with those of Koots et al. (1994b), who reported average estimates of genetic correlations at a constant age between marbling score and dressing percentage to be .25 . Pariacote et al. (1998) reported estimates of genetic correlations between marbling score and dressing percentage without a covariate to be nearly zero, .08 .

Similarly, estimates of genetic correlations between dressing percentage and longissimus muscle area were different depending on covariate in the model: -.11 with backfat thickness as covariate, .01 with slaughter age as covariate, and .91 with slaughter weight as covariate, respectively. These results indicate that selection for increased dressing percentage should result in increased longissimus muscle area with slaughter weight as an end point covariate but in little change with backfat thickness or slaughter age as an end point. The estimate with slaughter age as an end point was smaller than estimates reviewed by Koots et al. (1994b), who reported average estimates of genetic correlations at a constant age between dressing percentage and longissimus muscle area to be .36 . Pariacote et al. (1998) reported an estimate of genetic correlation without a covariate between dressing percentage and longissimus muscle area to be .79 .

Estimates of genetic correlations between marbling score and longissimus muscle area were not as different

Table 7. Parameter estimates (and standard errors when all traits were measured) from two-trait analyses for marbling score (MSC), dressing percentage (DRP), and marbling score (MSC) with different covariates included in the model

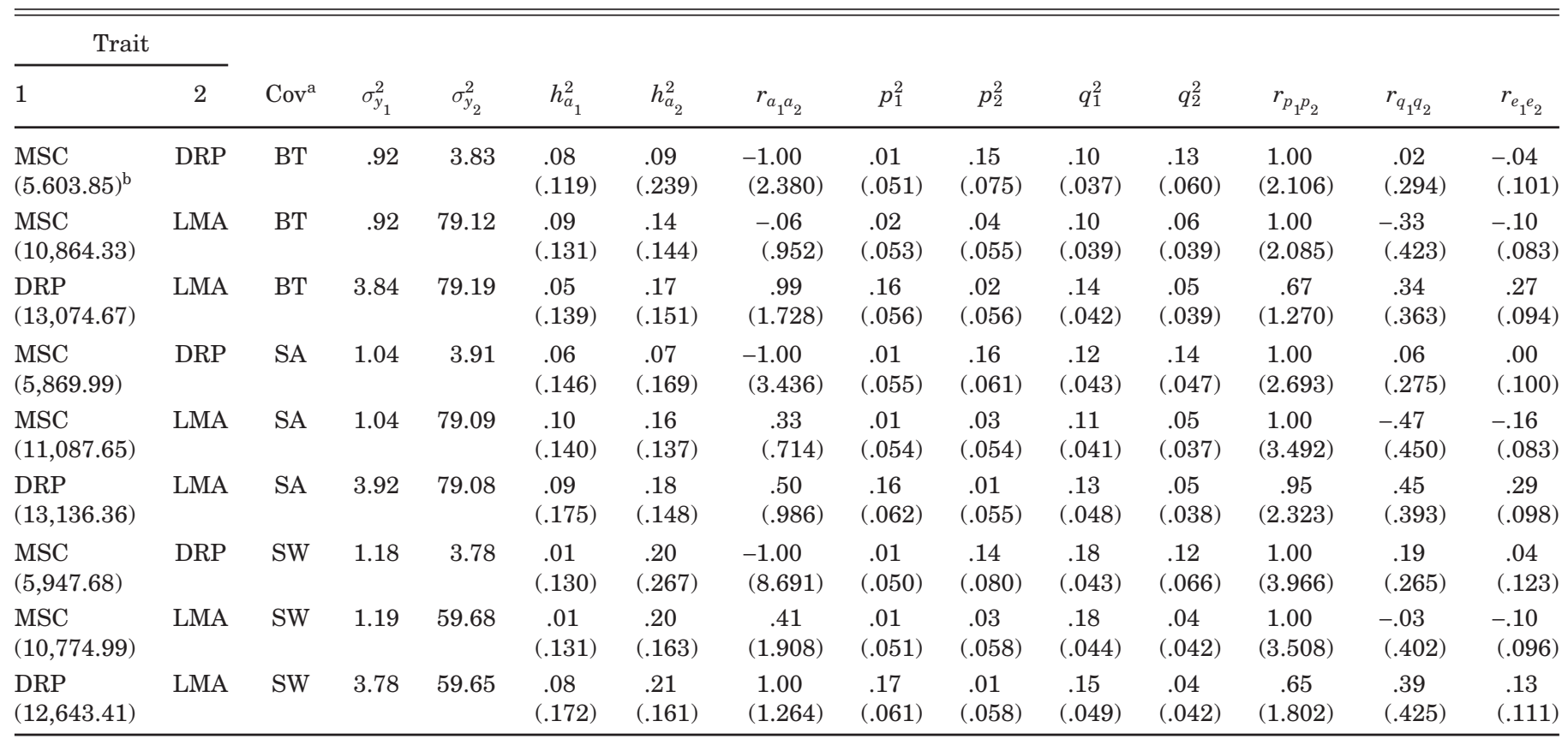

${ }^{\mathrm{a}} \mathrm{Cov}=$ covariate: $\mathrm{BT}=$ backfat thickness $(\mathrm{mm}), \mathrm{SA}=$ slaughter age $(\mathrm{d}), \mathrm{SW}=$ slaughter weight $(\mathrm{kg}) ; \sigma_{y_{i}}^{2}=$ phenotypic variance for trait $i$, $h_{a_{i}}^{2}=$ direct heritability for trait $i, r_{a_{i} a_{j}}=$ genetic correlation between direct effects for trait $i$ and $j, p_{i}^{2}=$ fraction of variance due to maternal effects for trait $i, q_{i}^{2}=$ fraction of variance due to sire $\times$ region $\times$ year-season interaction effects for trait $i, r_{p_{i} p_{j}}=$ correlation between maternal effects for traits $i$ and $j, r_{q_{i} q_{j}}=$ correlation between sire $\times$ region $\times$ year-season interaction effects for traits $i$ and $j$, and $r_{e_{i}} j_{j}=$ correlation between residual effects for traits $i$ and $j$.

b_2 times logarithm of likelihood. 
Table 8. Parameter estimates (standard errors) from two-trait analyses for marbling score (MSC) and dressing percentage (DRP), marbling score (MSC) and longissimus muscle area (LMA), and dressing percentage (DRP) and longissimus muscle area (LMA) with different covariates included in the model

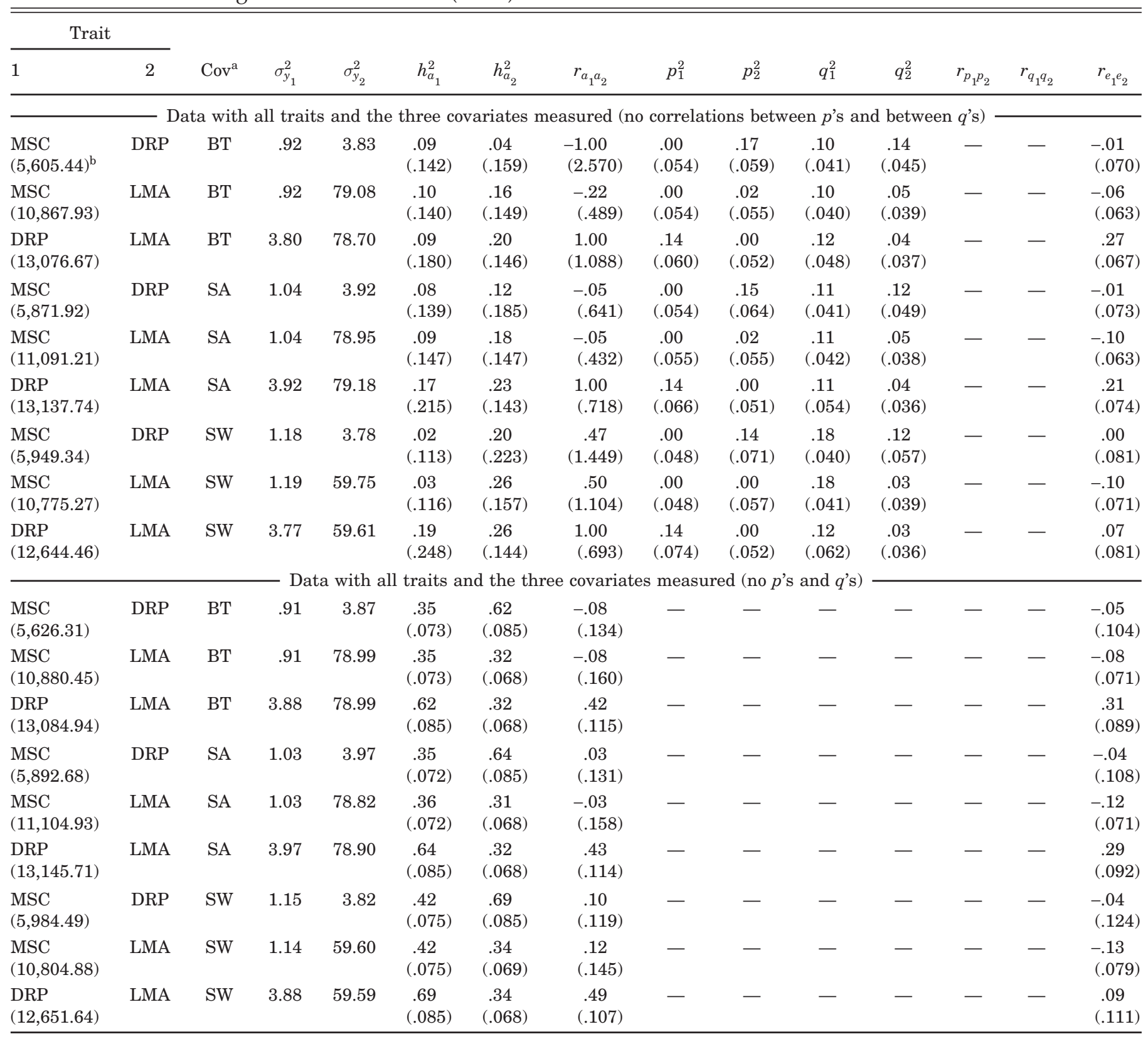

${ }^{\mathrm{a}} \mathrm{Cov}=$ covariate: $\mathrm{BT}=$ backfat thickness $(\mathrm{mm}), \mathrm{SA}=$ slaughter age $(\mathrm{d}), \mathrm{SW}=$ slaughter weight $(\mathrm{kg}) ; \sigma_{y_{i}}^{2}=$ phenotypic variance for trait $i$, $h_{a_{i}}^{2}=$ direct heritability for trait $i, r_{a_{i} a_{j}}=$ genetic correlation between direct effects for trait $i$ and $j, p_{i}^{2}=$ fraction of variance due to maternal effects for trait $i, q_{i}^{2}=$ fraction of variance due to sire $\times$ region $\times$ year-season interaction effects for trait $i, r_{p_{i} p_{j}}=$ correlation between maternal effects for traits $i$ and $j, r_{q_{i} q_{j}}=$ correlation between sire $\times$ region $\times$ year-season interaction effects for traits $i$ and $j$, and $r_{e_{i} e_{j}}=$ correlation between residual effects for traits $i$ and $j$.

b-2 times logarithm of likelihood.

for different covariates as with the other two correlations: .20 with backfat thickness as covariate, .47 with slaughter age as covariate, and .39 with slaughter weight as covariate. These estimates did not agree with those of Koots et al. (1994b), who reported average estimates of genetic correlations at a constant age between marbling score and longissimus muscle area to be -.21. Dinkel and Busch (1973) reported an estimate of direct genetic correlation between marbling score and longissimus muscle area to be -.17 .

The primary factor used by the beef industry to assign carcass quality is marbling score (Marshall, 1994). Genetic correlation between marbling score and longissimus muscle area with slaughter weight as a covariate was moderate (.39). Thus, selection for increased longissimus muscle area may result in increased carcass qual- 
ity (marbling score) for Korean Native Cattle marketed at a weight end point.

With any of the three (backfat thickness, slaughter age, or slaughter weight) covariates used in the model, estimates of fraction of variance due to maternal effects $\left(p^{2}\right)$ were small (.01) for marbling score, .15 to .16 for dressing percentage, and .01 to .03 for longissimus muscle area.

The pattern of estimates of heritability and genetic correlations was generally different when slaughter weight was used as the covariate rather than backfat thickness or slaughter age. The reason is not obvious, but one possibility is that the decision to slaughter might have been dependent on slaughter weight. Therefore, the data with all traits measured was analyzed without any covariate. The estimates shown in the bottom part of Table 6 do not provide any clues. The pattern of estimates is most similar to that for the same data with a slaughter age end point. The only clear point is that when slaughter weight is the covariate the phenotypic variance for longissimus muscle area is reduced compared to no covariate for end point or for backfat thickness and slaughter age end points.

Additional analyses were done to search for any reasons why the pattern of estimates is not similar with different end points. Parameter estimates from two-trait analyses are shown in Table 7, which shows the same pattern as that found with the three-trait analyses. The top of Table 8 also shows that the pattern of estimates was the same whether correlations between random sire $\times$ region $\times$ year-season interaction effects and between maternal effects were forced to be zero or not.

A simpler model including only direct and residual effects in the model was also tried. Estimates of heritabilities (the bottom of Table 8) were inflated compared to full models, indicating that sire $\times$ region $\times$ year-season interaction and(or) maternal effects are confounded with direct genetic effects. The pattern of different estimates of heritability and genetic correlations with slaughter weight rather than backfat thickness or slaughter age as end points was generally the same for all models.

\section{Implications}

The estimates of heritabilities for these carcass traits for Korean Native Cattle with a model including sire $\times$ region $\times$ year-season interaction were smaller than have been reported for other breeds. Reasons may be 1) the small number of records, 2) inaccurate data collection, which suggests the need to collect and identify more data more carefully, and 3) parameters for the breed are different. The results show that choice of end point covariate (backfat thickness, slaughter age, or slaughter weight) for the model seems to be important for genetic evaluation of carcass traits of Korean Native Cattle.

\section{Literature Cited}

Benyshek, L. L. 1981. Heritabilities for growth and carcass traits estimated from data on Herefords under commercial conditions. J. Anim. Sci. 53:49-56.

Boldman, K. G., L. A. Kriese, L. D. Van Vleck, C. P. Van Tassell, and S. D. Kachman. 1995. A manual for use of MTDFREML. A set of programs to obtain estimates of variances and covariances. ARS, USDA, Washington, DC.

Dinkel, C. A., and D. A. Busch. 1973. Genetic parameters among production, carcass composition and carcass quality traits of beef cattle. J. Anim. Sci. 36:832-846.

Graser, H. U., S. P. Smith, and B. Tier. 1987. A derivative-free approach for estimating variance components in animal models by restricted maximum likelihood. J. Anim. Sci. 64:1362-1370.

Hirooka, H., A. F. Groen, and M. Matsumoto. 1996. Genetic parameters for growth and carcass traits in Japanese Brown Cattle estimated from field records. J. Anim. Sci. 74:2112-2116.

Koots, K. R., J. P. Gibson, C. Smith, and J. W. Wilton. 1994a. Analyses of published genetic parameter estimates for beef production traits. 1. Heritability. Anim. Breed. Abstr. 62:309-338.

Koots, K. R., J. P. Gibson, C. Smith, and J. W. Wilton. 1994b. Analyses of published genetic parameter estimates for beef production traits. 2. Phenotypic and genetic correlations. Anim. Breed. Abstr. 62:825-853.

Lee, C., and E. J. Pollak. 1997. Relationship between sire $\times$ year interactions and direct-maternal genetic correlation for weaning weight of Simmental cattle. J. Anim. Sci. 75:68-75.

Marshall, D. M. 1994. Breed differences and genetic parameters for body composition traits in beef cattle. J. Anim. Sci. 72:2745-2755.

Pariacote, F., L. D. Van Vleck, and R. E. Hunsley. 1998. Genetic and phenotypic parameters for carcass traits of American Shorthorn Beef Cattle. J. Anim. Sci. 76:2584-2588.

Smith, S. P., and H.-U. Graser. 1986. Estimating variance components in a class of mixed models by restricted maximum likelihood. J. Dairy Sci. 69:1156-1165. 